\title{
Incidence, Mortality, Survival, and Prognostic Analysis of Epithelial Ovarian Cancer Patients in Brunei Darussalam: A Population-Based Study
}

\author{
Elvynna Leong ( $\square$ elvynna.leong@ubd.edu.bn ) \\ Faculty of Science, Universiti Brunei Darussalam \\ Sok King Ong \\ NCD Prevention Unit, Ministry of Health \\ Fadzilah Jali \\ Faculty of Science, Universiti Brunei Darussalam \\ Lin Naing \\ PAPRSB Institute of Health Sciences, Universiti Brunei Darussalam
}

\section{Research Article}

Keywords: epithelial ovarian cancer, incidence, mortality, age-standardized rates, survival, Brunei, prognosis

Posted Date: October 11th, 2021

DOI: https://doi.org/10.21203/rs.3.rs-954088/v1

License: (c) (i) This work is licensed under a Creative Commons Attribution 4.0 International License. Read Full License 


\section{Abstract \\ Background}

Ovarian cancer is the fifth most common cancer among females in Brunei Darussalam in 2017. This study aims to provide nationwide cancer statistics including cancer incidence, mortality, survival rates for women diagnosed with epithelial ovarian cancer, and evaluate the prognostic factors of epithelial ovarian cancer patients survival in Brunei Darussalam.

\section{Methods}

This is a retrospective population-based study of patients diagnosed with epithelial ovarian cancer between 1 st January 2007 and 31 st December 2017 in Brunei Darussalam. Crude, age-specific, age-standardized incidence and mortality rates per 100,000 women were calculated. Kaplan-Meier survival analysis method was used to determine the overall 5-years survival rate of epithelial ovarian cancer patients. Log-rank test was used to examine the differences in survival between groups. The Multivariable Cox Proportional Hazard (PH) regression models were used to estimate the hazard ratio (HRs) for overall survival and to identify the prognostic factor of epithelial ovarian cancer patients. $\mathrm{PH}$ assumption over time for these models were evaluated.

\section{Results}

A total of 207 patients were included in the study. The crude incidence and mortality rates were 9.7 and 3.6 per 100,000 respectively while the age-standardized incidence and mortality rates were $11.3(95 \% \mathrm{Cl}$ : $9.7,12.9)$ and $4.5(95 \% \mathrm{Cl}: 3.4,5.6)$ per 100,000 respectively in the period 2007-2017. The overall mean age at diagnosis was 48.4 (standard deviation=15.3) years. The overall survival rates at 1,3 , and 5 years for epithelial ovarian cancer patients were $79.7 \%, 69.7 \%$, and $61.4 \%$ respectively. Age at diagnosis, district, cancer stage, and histology were the significant prognostic factors for epithelial ovarian cancer patients' survival. Older age at diagnosis ( $\geq 70$ years vs $<40$ years), regional or advanced stage (vs localized stage) and having undifferentiated or other epithelial ovarian (vs serous carcinoma) were associated with having higher hazard of death while patients residing in Belait district (vs Brunei Muara) was associated with having lower hazard.

\section{Conclusion}

More efforts and research should be made to detect the disease at early stage through education and public awareness to ensure the availability of high-quality care for all women with ovarian cancer and to improve the survival rates of patients with ovarian cancer.

\section{Introduction}

Ovarian cancer is the eighth most commonly diagnosed cancer in female and the eighteenth most common cancer worldwide ${ }^{[1,2]}$. It is one of the most common gynecologic cancers that ranks third after cervical and uterine cancer ${ }^{[1,3]}$ and is associated with having the worst prognosis and the highest mortality rate ${ }^{[4]}$. Although ovarian cancer has a lower prevalence in comparison with breast cancer, it is three times more lethal ${ }^{[5]}$.

According to GLOBOCAN 2020, there were 313,959 new cases of ovarian cancer and 207,252 death cases in year 2020. More than half of the new cases were from Asia (54.4\%), followed by Europe (21.2\%), Northern America (8.5\%), Africa (7.7\%), Latin America and the Carribean (7.5\%), and Oceania (0.7\%). Asia also recorded highest mortality from ovarian cancer in year $2020(54.4 \%)$ while Europe came second with $21.3 \%{ }^{[2]}$. In 2017, ovarian cancer was the fifth most common cancer among females in Brunei Darussalam ${ }^{[6]}$. Like many cancers, the incidence of ovarian cancer varies across the world. GLOBOCAN 2020 estimates of age-standardized (world) incidence rates and mortality rates of ovarian cancer in Brunei Darussalam were 17.4 per 100,000 and 7.4 per 100,000 respectively ${ }^{[7]}$.

Brunei Darussalam is located in the northern part of Borneo in South East Asia with an estimated population of 453,600 in 2020. Brunei Citizens accounted for the largest portion of 336,000 (74.1\%) while Permanent Residents and Temporary Residents were 33,7000 (7.4\%) and 83,900 (18.5\%) respectively. Brunei is a multiracial and multicultural society where the major ethnic groups are Malay (65.8\%), Chinese (10.2\%) and other ethnicities (24.0\%). There are four districts namely Brunei Muara (69.7\%), Tutong (11.4\%), Belait (16.5\%) and Temburong $(2.5 \%)^{[8]}$. Health services are highly accessible and provided free to citizens and permanent residents of the country, including provision for overseas specialized medical care not available in the country. The country's health care system uses an electronic medical record system 
since September 2012 to implement an efficient, effective healthcare information and management system, in line with international best practices, which enhance the accuracy, timeliness, and completeness of the country's cancer registry ${ }^{[9]}$.

This study aims to provide nationwide cancer statistics including cancer incidence, mortality and survival rates for women diagnosed with epithelial ovarian cancer in 2007-2017, and evaluate the prognostic factors of epithelial ovarian cancer patients survival in Brunei Darussalam.

\section{Materials And Methods}

This is a retrospective population-based study using de-identified data extracted from the Brunei Darussalam Cancer Registry (BDCR) of Ministry of Health, Brunei Darussalam. Female Brunei citizens and permanent residents who were diagnosed with ovarian cancer between $1 \mathrm{st}$ January 2007 and 31st December 2017 were included in the study. All cases followed until 31st December 2018. All these eligible cases were included without sampling. Age at diagnosis was classified as $<40,40-49,50-59,60-69, \geq 70$ years old, and ethnicity was stratified into Malay, Chinese and Others. District was classified as Brunei Muara, Tutong, Belait and Temburong. Cancer staging information at time of diagnosis reported in BDCR was based on the Surveilance, Epidemiology, and End Results (SEER) summary staging, which categorizes ovarian cancer spread from its origin into localized, regional and distant ${ }^{[10]}$.

Histology types were categorized according to the third revision of the International Classification of Diseases for Oncology (ICD-0-3) histology codes ${ }^{[11]}$. Only cases of epithelial ovarian cancer (ICD-0-3 C56) diagnosed between 2007 and 2017 were included in the analysis whereas non-epithelial (e.g. germ cell, sex cord-stromal) were excluded from the analysis. Histological subtypes were categorized as serous carcinoma $(8050,8441,8450,8460,8461)$, mucinous carcinoma $(8470,8471,8480,8490)$, endometroid carcinoma $(8380,8560)$, clear cell carcinoma (8310), and undifferentiated or other epithelial $(8010,8020,8070,8140,8141,8246,8260,8440,8500,8510,8980)$ whereas all patients with borderline tumours (8442) were excluded.

The incidence and mortality rates of epithelial ovarian cancer in the population over the study period were described. Crude, age-specific, agestandardized incidence and mortality rates per 100,000 women were calculated for the period 2007-2017. Crude rate and age-specific rate were calculated using the number of new cases/deaths divided by Brunei female population during the same period ${ }^{[12]}$. The annual agestandardized incidence rates (ASIR) and mortality rates (ASMR) were standardized by the direct method using the World Health Organization (WHO) world standard population distribution ${ }^{[13]}$. Patients were categorized into two time-periods, 2007-2011 and 2012-2017, to compare the change in the crude, age-specific and age-standardized incidence and mortality rates over time.

Survival statistics were used to estimate cancer patients' prognosis which is of great interest to patients, clinicians, researchers, and policy makers ${ }^{[14]}$. Descriptive statistics analyses were conducted to evaluate the distribution of each variable, followed by the Fisher's Exact test to analyze associations between cancer stages and other variables. Kaplan-Meier survival analysis method was used to determine the overall 5years survival rate and the median survival time of epithelial ovarian cancer patients. Overall survival was defined as the period of time from diagnosis to death or end of follow-up, due to any cause. Patients who were still alive or lost to follow-up at the end of the study period were right-censored. Log-rank test was used to examine the differences in survival between groups. Multivariable Cox Proportional Hazard (PH) regression models were used to estimate the hazard ratio (HRs) for overall survival and to identify the prognostic factor of epithelial ovarian cancer patients. HR indicates the relative risk of dying in the defined period compared to a reference group. When the HR is below 1.0, the risk is lower compared to the reference group. We evaluated the PH assumption over time for these models using Schoenfeld residuals and by plotting the log of the negative log of the survival function against log of time. Adjusted hazard ratios and $95 \%$ confidence intervals (Cl) were generated. All statistical analyses were performed using the R statistical software (Version 4.0.2).

\section{Ethical approval}

for this study was obtained from Pengiran Anak Puteri Rashidah Sa'adatul Bolkiah Institute of Health Sciences Research and Ethics Committee, the Medical and Health Research Ethics Committee of Ministry of Health, Brunei Darussalam [Ref: UBD/PAPRSBIHSREC/2018/149] and University Research Ethics Committee, Universiti Brunei Darussalam [Ref: UBD/OAVCR/UREC/Apr202003].

\section{Results}

A total of 207 patients diagnosed with epithelial ovarian cancer were included in this study. The highest number of cases were recorded in year 2013 and 2014 ( $n=24$ cases, 11.6\%) while the lowest was in year 2007 ( $n=9$ cases, 4.3\%), with an average of 18 cases per year. There were 77 deaths in total during the study period and a total of 73 cases had died within 5 years of diagnosis. 
The crude incidence rate of epithelial ovarian cancer was 9.7 per 100,000 per year while crude mortality rate was 3.6 per 100,000 in the period 2007 to 2017 (Table 1). Crude incidence rate was 8.7 per 100,000 in the first period (2007-2011) and increased to 10.5 per 100,000 in the second period (2012-2017). However, crude mortality rate was more than double in the second period (4.9 per 100,000$)$ as compared to the first period (1.8 per 100,000).

Age-specific incidence and mortality rates in the period 2007 to 2017 are shown in Figure 1. The lowest incidence rate was seen in patients below 40 years old (3.8 per 100,000) and the rates increased to 31.7 per 100,000 women in the 50-59 age group. A decrease was noted in those who were in the $60-69$ age group $(27.3$ per 100,000$)$ but the rate continued to increase to 34.4 per 100,000 for 70 years and above age group. The same trend can be seen for the age-specific mortality rates where patients below 40 years old recorded the lowest rate ( 0.3 per 100,000), followed by 40-49 age group (5.2 per 100,000), 60-69 years (13.1 per 100,000), 50-59 years (17.5 per 100,000) and 70 years and above (19.9 per 100,000). Age-specific incidence rates increased steadily with age for both time periods, with a drop in the 60-69 age group. However, incidence rates increased for the oldest age group ( years) in the first period (57.0 per 100,000) while incidence continued to decline in the second period (20.4 per 100,000). In the first period, age-specific mortality rates increased with age and peaked at 60-69 years (16.4 per $100,000)$ before beginning to decline in the oldest age group (14.2 per 100,000). Similar to the first group, mortality rates in the second period increased with age but dropped in the 60-69 age group (11.5 per 100,000) before continuing to increase in the oldest age group (23.4 per 100,000).

The ASIR by for epithelial ovarian cancer was 11.3 (95\% Cl: 9.7, 12.9) per 100,000 while the ASMR was 4.5 (95\% Cl: $3.4,5.6)$ per 100,000 in the period 2007-2017 (Table 1). The ASIR was lower in the first period with 11.6 (95\% Cl: $8.9,14.3)$ per 100,000 compared to the second period with 11.1 (95\% Cl: 9.1, 13.1) per 100,000. However, the ASMR increased in the second period with 5.6 (95\% Cl: $3.1,8.1)$ per 100,000 from 3.0 (95\% Cl: $1.5,4.5)$ per 100,000 in the first period.

Patients' demographic and clinical characteristics are presented in Table 2. The overall mean age at diagnosis was 48.4 (standard deviation = $15.3)$ years, with the majority of the patients in the $50-59$ age group (29.0\%), followed by less than 40 years (27.5\%), $40-49$ years old (22.2\%), $60-69$ years old (12.1\%) and 70 years old and above (9.2\%). Majority of the patients were of Malay ethnicity (83.6\%) while $10.6 \%$ and $5.8 \%$ were of Chinese and other ethnicities respectively. Most epithelial ovarian cancer patients resided in Brunei Muara district (68.2\%), followed by Tutong (16.2\%), Belait (13.6\%) and Temburong (2.0\%). Majority of the patients were diagnosed at localized stage (38.9\%), followed by distant (33.7\%), and regional stages (27.4\%). The most common histological type was mucinous carcinoma (30.9\%), followed by serous carcinoma (28.0\%), undifferentiated or other epithelial (25.1\%), endometrioid carcinoma (10.6\%) and clear cell carcinoma (5.3\%).

Table 3 reports the number of cases for epithelial ovarian cancer patients according to cancer stage. No significant differences in the proportion of districts $(p=0.350)$ and ethnicities $(p=0.443)$ were found between stages. More than half of the women aged 70 and above were diagnosed at distant stage (52.9\%) while only $11.8 \%$ were diagnosed at localized stage. Approximately $62.5 \%$ of women aged $60-69$ years were diagnosed at distant stage. However, most of the women aged 40 and below were diagnosed at localized stage (69.8\%), followed by regional (17.0\%) and distant stage (13.2\%). Almost half of the total women with serous carcinoma histology were diagnosed at distant stage (49.0\%), followed by regional (29.4\%) and localized (21.6\%). However, patients with mucinous carcinoma and clear cell carcinoma reported majority of them were diagnosed at localized stage.

The overall survival rates at 1, 3, and 5 years for epithelial ovarian cancer patients in Brunei Darussalam were 79.7\% (95\% C.I.: 73.6, 84.6), 69.7\% (95\% C.I.: 62.8, 75.6), and 61.4\% (95\% C.I.: 53.9, 68.1) respectively (Figure 2). However, the median survival time was not available as the estimated survival were above 0.5 . Table 2 presents the 5 -year survival rates and $p$-values of the log-rank test for each covariate. This study found significant differences in epithelial ovarian cancer patients' survival age groups $(p<0.001)$, cancer stage $(p<0.001)$ and histology $(p<0.001)$. The 5 -year survival rate was highest for age group 40 years and below (92.6\%), followed by $40-49$ years (66.6\%), 60-69 years (43.9\%), 70 years and above (40.5\%) and $50-59$ years (40.4\%), shown in Figure 3.

Epithelial ovarian cancer patients resided in Brunei Muara district (57.8\%) had the lowest survival compared to the other districts. However, this study found no significant difference in survival between the four districts $(p=0.229)$. There was also no significant difference in survival between ethnicities $(p=0.241)$. The 5 -year survival rates for cancer stages were $94.1 \%, 46.4 \%$ and $38.0 \%$ for localized, regional, and distant stages respectively (Figure 4). For histological subtypes, mucinous carcinoma had the highest 5-year survival rate (78.5\%), followed by clear cell carcinoma (68.2\%), serious carcinoma (62.3\%), endometroid carcinoma (55.8\%), and undifferentiated or other epithelial (39.6\%) (Figure 5).

Multivariate Cox $\mathrm{PH}$ regression analyses found that age at diagnosis, district, cancer stage, and histology were the significant prognostic factors for epithelial ovarian cancer patients' survival $(p<0.05)$, shown in Table 4 . No evidence of significant violations of proportional hazard assumptions were observed. 
As compared to a patient below 40 years old, the expected hazard of death was highest for epithelial ovarian cancer patient in the oldest age group ( 70 years) [Adj. HR=7.21, 95\% Cl: 2.24, 23.23, $p=0.001$ ], followed by 50-59 years [Adj. HR=5.29, 95\% Cl: 1.99, 14.05, $p=0.001$ ] whereas the expected hazard of patients in the 40-49 and 60-69 age groups were found to be comparable to those below 40 years old ( $p>0.05$ ). Patients residing in Belait district have significantly lower hazard of death [Adj. HR=0.31, 95\% Cl: $0.12,0.80, p=0.015]$ compared to those residing in Brunei Muara.

Patients with distant stage have significantly higher hazard [Adj. HR=11.99, 95\% Cl: 4.46, 32.23, $p<0.001]$ compared to patients with localized stage. This trend is also observed in patients with regional stage [Adj. $\mathrm{HR}=6.12,95 \% \mathrm{Cl}: 2.26,16.56, p<0.001]$. Patients with undifferentiated or other epithelial have significantly higher hazard of death [Adj. $\mathrm{HR}=3.12,95 \% \mathrm{Cl}$ : $1.63,5.95, p=0.001]$ compared to patients with serous carcinoma. No significant differences were found in the hazards of death when comparing a patient with serous carcinoma with mucinous carcinoma ( $p=0.153)$, endometrioid carcinoma $(p=0.132)$, and clear cell carcinoma $(p=0.664)$.

\section{Discussion}

Epithelial ovarian cancer is the most lethal gynecologic cancer affecting women globally ${ }^{[15,16]}$ and accounts for $90 \%$ of all ovarian malignancies ${ }^{[17,18]}$. There are large variations in the incidence rate of ovarian cancer in different areas of the world. The world's ASIR of ovarian cancer in year 2012, 2018 and 2020 were 6.1, 6.6 and 6.6 per 100,000 women respectively [1,3, 15]. Brunei Darussalam recorded the third highest standardized incidence rate of ovarian cancer (8.8 per 100,000) among Asian countries in year 2012 ${ }^{\text {[19] }}$. Adjusting crude epithelial ovarian cancer incidence rate $(9.7$ per 100,000$)$ for WHO world standard population in this study revealed an ASIR of 11.3 per 100,000 . Our rates were considerably higher compared to the world's average ASIR of all ovarian cancers. Past study has found a significant positive correlation between the Human Development Index (HDI) and the standardized incidence rate of ovarian cancer, which means that incidence was higher among high HDI countries ${ }^{[19]}$. Brunei Darussalam's HDI was 0.838 in year 2019 which put the country in the very high human development country ${ }^{[20]}$. Ovarian cancer incidence pattern may be explained by changes in risk factors related to lifestyle, population

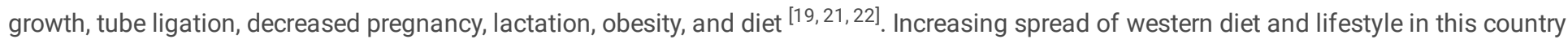
might also be the cause of the rapid increase in the burden of the disease.

The world's average ASMR of ovarian cancer in 2012 was 3.8 (per 100,000) and the rate increased to 3.9 (per 100,000) in 2018 and 4.2 (per 100,000 ) in $2020^{[1,3,15]}$. In this study, our crude epithelial ovarian cancer mortality was 3.6 (per 100,000) but ASMR was 4.5 (per 100,000), when standardized using WHO world standard population. Our rate was higher compared to the average world's mortality rate for women diagnosed with ovarian cancer. Our study showed a decrease in ASIR trend of epithelial ovarian cancer between the two time periods (11.6 vs 11.1 per 100,000). Comparison of the age-specific incidence rates between the two time periods showed incidence in women aged 70 years and above was much higher in the first period (57.0 vs 20.4 per 100,000), which might have contributed to the drop in ASIR in the second period. However, the ASMR was higher in the second period (5.6 vs 3.0 per 100,000). The high mortality rate observed in the second period was due to the higher age-specific mortality rates for all the age-groups, except for women aged 60 to 69 years, as compared to the first period.

This is the first study looking at the overall survival rates and prognostic factors of epithelial ovarian cancer in Brunei Darussalam. The overall survival rates at 1-, 3- and 5-year for epithelial ovarian cancer patients in Brunei Darussalam were 79.7\%, 69.7\%, and 61.4\% respectively. Studies from other Asian countries reported 5-year overall survival rates among ovarian cancer patients of 35.2\% in Malaysia [23], $54.8 \%$ in Indonesia ${ }^{[24]}$ and Singapore reported 5 -year relative survival of $42.7 \%{ }^{[25]}$. Another study in Malaysia reported overall survival rate of $51.2 \%{ }^{[26]}$ and Australia had 5-year overall survival rate of $59.9 \%{ }^{[27]}$.

Age of diagnosis was a prognostic factor for patients of epithelial ovarian cancer in this study. It is commonly reported that the risk of epithelial ovarian cancer is strongly related to age, highest in older females. Our study found that approximately half of the patients with epithelial ovarian cancer were diagnosed at a younger age (<50 years) and survival varied considerably by age groups. Younger patients had better 5-year survival than older patients, consistent with other large population-based studies [28-30]. Specifically, 5-year survival in this study was $92.6 \%$ for women aged below 40 years at diagnosis, while survival ranged from $40.4-43.9 \%$ for women aged 50 and above at diagnosis. Better survival in younger women may be related to the fact that older women are more likely to have other health problems. In addition, ovarian cancer may be diagnosed earlier in pre-menopausal women than in post-menopausal women, because one major symptom used to identify ovarian cancer is a change in menstruation ${ }^{[31]}$. Earlier diagnosis means that the cancer is less likely to have spread beyond the ovaries and therefore, the chances of survival are better.

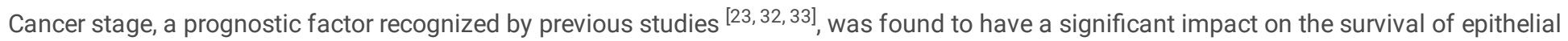
ovarian cancer patients in this study. About $33.7 \%$ of the total cases were diagnosed at distant stage. This study found patients with distant 
stage have significantly higher hazard compared to patients with localized and regional stages, consistent with numerous studies ${ }^{[32-35]}$. More than half of the women aged 70 and above $(52.9 \%)$, and approximately $62.5 \%$ of women aged between 60 to 69 were diagnosed at distant stage. In most cases, ovarian cancer is not diagnosed until it has progressed to an advanced stage and the cancer has spread beyond the ovaries which explains the lower survival from ovarian cancer ${ }^{[36]}$. This is because ovarian cancer symptoms in the early stage are not noticeable ${ }^{[37]}$.

Histological type is another prognostic factor for epithelial ovarian cancer patients in this study. While serous carcinoma is reported to be the most common histological type ${ }^{[38,39]}$, majority of the patients in this study were diagnosed with mucinous carcinoma histological type (30.9\%), followed by serious carcinoma (28.0\%). Our data showed the 5 -year survival of patients with mucinuous carcinoma or clear cell carcinoma was better than those of serous carcinoma, endometroid carcinoma, and undifferentiated or other epithelial. Although the current managements for epithelial ovarian carcinoma were similar regardless different histological types ${ }^{[40]}$, the modification of the treatments based on the histological types is necessary especially for patients with undifferentiated carcinoma or other epithelial because of their poorer outcome.

Across districts, we found patients in Brunei Muara district had the lowest survival rate (57.8\%). Although this study found no significant difference in survival between the four districts, multivariable Cox PH analysis shows patients residing in Belait district have significantly lower hazard of death compared to those residing in Brunei Muara. For ethnicities, although Chinese ethnicity showed higher survival rate (81.8\%) as compared to the Malays (58.9\%), our study demonstrated that there is no significant difference in overall survival between ethnicities.

Epithelial ovarian cancer, although less common compared to the other gynecological cancers, is the most deadly. We found that the 5-year survival rate of ovarian cancer patients is $61.4 \%$, lower as compared to the other gynecologic cancer in Brunei Darussalam such as cervical cancer with 5 -year survival rate of $68.6 \%{ }^{[41]}$. However, there has been an improvement in the survival of patients diagnosed with ovarian cancer during the last 20 years. Treatments for ovarian cancer have improved over time, such as the development of adjuvant therapy with platinum-based drugs, tumor cytoreductive surgery, taxane-based chemotherapy, and intraperitoneal delivery of chemotherapy ${ }^{[42-45]}$.

In summary, our data showed that age at diagnosis, cancer stage, histology and district are prognostic factors for epithelial ovarian cancers. In particular, our study showed that older age at diagnosis ( $\geq 70$ years vs $<40$ years), regional or advanced stage (vs localized stage) and having undifferentiated or other epithelial ovarian (vs serous carcinoma) were associated with having higher hazard of death while patients residing in Belait district (vs Brunei Muara) was associated with having lower hazard.

Although the present study's findings are strengthened by the large nationally representative of Bruneian women, there are also several limitations. First, data were collected retrospectively and were based on the inherent accuracy of patient records. Therefore, our study may have biases especially with incomplete data collection. Second, cancer treatment, which is an important prognostic factor for ovarian tumours ${ }^{[2,35]}$, is not available for this study. Other potential prognostic factors that have been reported in other studies such as BMI at diagnosis, CA125 levels, first-degree family history of cancer, grade of cancer, gene expression and marital status are also not available $[34,46-48]$. Future studies should include these potential prognostic factors which would be useful for examining the impact of early diagnosis of survival and could contribute to understanding some of the variation observed between countries.

Despite these limitations, the findings of the present study provide clinicians, policy makers, researchers, patients, caregivers, and public health professionals with key data to know where improvements have been made and where more support is needed in Brunei Darussalam. Future studies may be conducted to identify the contributing factors of higher proportion of late stage cancer in the older age population to help guide prevention and screening strategies. The relatively high proportion of advanced stage presentation of epithelial ovarian cancer calls for increasing awareness among women about early symptoms of ovarian cancer. More efforts and research should be made to detect the disease at early stage through education and public awareness to ensure availability of high-quality care for all women with ovarian cancer and improve the survival rates of patients with ovarian cancer.

\section{Abbreviations}

PH: Proportional Hazards

HR: Hazard Rate

Cl: Confidence Interval

BDCR: Brunei Darussalam Cancer Registry 
SEER: Surveilance, Epidemiology, and End Results

ICD-0-3: Third revision of the International Classification of Diseases for Oncology

ASIR: Age-Standardized Incidence Rates

ASMR: Age-Standardized Mortality Rates

WHO: World Health Organization

Adj. HR: Adjusted Hazard Rate

HDI: Human Development Index

SR: Survival Rate

\section{Declarations}

\section{Ethics approval and consent to participate}

Ethical approval for this study was obtained from Pengiran Anak Puteri Rashidah Sa'adatul Bolkiah Institute of Health Sciences Research and Ethics Committee, the Medical and Health Research Ethics committee of Ministry of Health, Brunei Darussalam [Ref:

UBD/PAPRSBIHSREC/2018/149] and University Research Ethics Committee, Universiti Brunei Darussalam [Ref: UBD/OAVCR/UREC/Apr202003].

\section{Consent for publication}

Not applicable. Participants' data were de-identified and this study did not involve any patient contact.

\section{Availability of data and materials}

The data that supports the findings of this study are available from Ministry of Health Brunei Darussalam but restrictions apply to the availability of these data, and so are not publicly available. Data are however available from the corresponding author upon reasonable request and with permission of Ministry of Health Brunei Darussalam.

\section{Conflict of interest:}

The authors declare that there is no conflict of interest.

\section{Funding}

The authors received no financial support for the research.

\section{Authors' contributions}

EL, OSK and FJ designed the research, EL and FJ analyzed the data, EL wrote the paper, and EL, OSK and LN critically revised the manuscript for important intellectual content.

\section{Acknowledgements}

The authors would like to thank the following organization: 1) Ministry of Health, Brunei Darussalam for provision of de-identified data for this study, 2) PAPRSB Institute of Health Sciences Research Ethics Committee (IHSREC), the Medical and Health Research Ethics Committee of Ministry of Health (MHREC), and University Research Ethics Committee of Universiti Brunei Darussalam for ethics approval for this study.

ORCID number: Dr Elvynna Leong (0000-0002-0728-9762), Dr. Ong Sok King (000-0001-8176-8561), Fadzilah Jali (0000-0002-3128-9228), Dr Lin Naing (0000-0003-1723-9854)

\section{References}

1. Sung H, Ferlay J, Siegel EL, Laversanne M, Soerjomataram I, Jemal A, et al. Global Cancer Statistics 2020: GLOBOCAN Estimates of Incidence and Mortality Worldwide for 36 Cancers in 185 Countries. CA Cancer J Clin. 2021, 71(3):209-249. 
2. World Health Organization (WHO). International Agency for Research on Cancer. Global Cancer Observatory (GLOBOCAN). 2020. Ovary [Fact sheet]. https://gco.iarc.fr/today/data/factsheets/cancers/25-Ovary-fact-sheet.pdf Accessed 1st April 2021.

3. Bray F, Ferlay J, Soerjomataram I, Siegel R, Torre L, Jemal A. Global Cancer Statistics 2018: GLOBOCAN estimates of incidence and mortality worldwide for 36 cancers in 185 countries. CA Cancer J CLIN, 2018, 68(6):394-424.

4. Coburn S, Bray F, Shermann M, Trabert B. International patterns and trends in ovarian cancer incidence, overall and by histologic subtype. Int J Cancer. 2017, 140(11):2451-2460.

5. Yoneda A, Lendorf ME, Couchman JR, Multhaupt HAB. Breast and ovarian cancers: a survey and possible roles for the cell surface heparan sulfate proteoglycans. J Histochem Cyctochem. 2012, 60(1):9-21.

6. Department of Policy and Planning, Ministry of Health Brunei Darussalam. Health Information Booklet 2017. 2018. http://www.moh.gov.bn/Downloadables/Health\%20Information\%20Bookler\%202017\%20(revised\%20as\%20of\%20January\%202019).pdf Accessed 2 October 2021.

7. World Health Organization (WHO). International Agency for Research on Cancer. Global Cancer Observatory (GLOBOCAN) 2020. Brunei Darussalam [Fact Sheet]. https://gco.iarc.fr/today/data/factsheets/populations/96-brunei-darussalam-fact-sheets.pdf Accessed 16 September 2021.

8. Department of Economic Planning and Statistics (DEPS), Ministry of Finance and Economy, Brunei Darussalam. Population. 2019. http://www.deps.gov.bn/SitePages/Population.aspx. Accessed 14 September 2021.

9. Leong E, Madli F, Ong SK. Five-year survival rate of breast cancer patients in Brunei Darussalam. Brunei Int Med J. 2019, 15:73-81.

10. Young JL Jr, Roffers SD, Ries LAG, Fritz AG, Hurlburt AA (eds). SEER Summary Staging Manual - 2000: Codes and Coding Instructions, National Cancer Institute, NIH Pub. No. 01-4969, Bethesda, MD, 2001.

11. Fritz A, Percy C, Jack A, Shanmugarathan S, Sobin L, Parkin D, et al. International classification of diseases for oncology (ICD-O) 3rd ed. Geneva, Switzerland: World Health Organization, 2000.

12. Department of Statistics, Department of Economic Planning and Statistics, Ministry of Finance and Economy, Brunei Darussalam. Population. Population by Age Group and Sex. eData Library. 2020. http://www.deps.gov.bn/SitePages/eData\%20library.aspx Accessed 30 September 2021.

13. Ahmad OB, Boschi-Pinto C, Lopez AD, Murray CJL, Lozano R, Inoue M. Age standardization of rates: A New WHO standard. Global Programme on Evidence Discussion Paper Series: No. 31. Geneva, WHO, 2000.

14. Mariotto AB, Noone AM, Howlader N, Cho H, Keel GE, Garshell J, et al. Cancer survival: an overview of measures, uses, and interpretation. JNCI Monographs. 2014, 2014 (49):145-186.

15. Ferlay J, Soerjomataram I, Dikshit R, Eser S, Mathers C, Rebelo M, et al. Cancer incidence and mortality worldwide: sources, methods and major patterns in GLOBOCAN 2012. Int J Cancer. 2015,136:E359-E386.

16. Kurosaki A, Hasegawa K, Kato T, Abe K, Hanaoka T, Miyara A, et al. Serum folate receptor alpha as a biomarker for ovarian cancer: implications for diagnosis, prognosis and predicting its local tumor expression. Int J Cancer. 2016,138:1994-2002.

17. Jelovac D, Armstrong DK. Recent progress in the diagnosis and treatment of ovarian cancer. CA Cancer J Clin. 2011, 61(3):183-203.

18. Torre LA, Trabert B, DeSantis CE, Miller KD, Samimi G, Runowic CD, et al. Ovarian Cancer Statistics, 2018. CA Cancer J Clin. 2018, 68, 284296.

19. Razi S, Ghoncheh M, Mohammadian-Hafshejani A, Aziznejhad H, Mohammadian M, Salehiniya H. The incidence and mortality of ovarian cancer and their relationship with the Human Development Index in Asia. 2016, 10: 628.

20. UNDP. Human Development Report 2020. The Next Frontier: Human Development and the Anthropocene. Brunei Darussalam. 2020. http://hdr.undp.org/sites/default/files/Country-Profiles/BRN.pdf Accessed 21 September 2021

21. Rohani-Rasaf M, Abdollahi M, Jazayeri S, Kalantari N, Asadi-Lari M. Correlation of cancer incidence with diet, smoking and socioeconomic position across 22 districts of Tehran in 2008. Asian Pacific J Cancer Prev.2013,14(3):1669-76.

22. Jemal A, Center MM, DeSantis C, Ward EM. Global patterns of cancer incidence and mortality rates and trends. Cancer epidemiology, biomarkers \& prevention : a publication of the American Association for Cancer Research, cosponsored by the American Society of Preventive Oncology. 2010,19(8):1893-907.

23. Lokman N, Hamid SAA, Bachok N. Survival study and prognostic factors of ovarian cancer registered in a teaching hospital in Malaysia. Sains Malaysiana. 2017, 46(4):559-565.

24. Aziz MF. Gynecological cancer in Indonesia. J Gynecol Oncol. 2009, 20 (1):8-10.

25. National Registry of Diseases Office (NRDO). Singapore Cancer Registry Annual Report, National Registry of Diseases Office, Ministry of Health, Singapore. 2018. Cancer Survival in Singapore 1973 - 2012. https://www.nrdo.gov.sg/docs/librariesprovider3/default-documentlibrary/scr-annual-report-2018.pdf?sfvrsn=bcf56c25_0 Accessed 2 Oct 2021. 
26. National Cancer Registry (NCR), National Cancer Institute, Ministry of Health, Malaysia. 2018. Malaysian Study on Cancer Survival (MySCan).

https://www.moh.gov.my/moh/resources/Penerbitan/Laporan/Umum/Malaysian_Study_on_Cancer_Survival_MySCan_2018.pdf Accessed 27 May 2021.

27. Playdon MC, Nagle CM, Ibiebele TI, Ferrucci LM, Protani MM, Carter J, et al. Pre-diagnosis diet and survival after a diagnosis of ovarian cancer. British Journal of Cancer. 2017, 116:1627-1637.

28. Chan JK, Urban R, Cheung MK, Osann K, Shin JY, Husain A, et al. Ovarian cancer in younger vs older women: a population-based analysis. Br J Cancer 2006a, 95:1314-20.

29. Cabanes A, Vidal E, Perez-Gomez B, Aragones N, Lopez-Abente G, Pollan M. Age-specific breast, uterine and ovarian cancer mortality trends in Spain: changes from 1980 to 2006. Cancer Epidemiol. 2009, 33:169-75.

30. Chan JK, Cheung MK, Husain A, Teng NN, West D, Whittemore AS, et al. Patterns and progress in ovarian cancer over 14 years. Obstet Gynecol. 2006b,108(3 Pt 1):521-8.

31. Akhtar-Danesh N, Elit L, Lytwyn A. Temporal trends in the relative survival among patients diagnosed with ovarian cancer in Canada 1992-2005: A population-based study. Gynecologic Oncology. 2011,123(2):192-195.

32. Lee JY, Kim S, Kim YT, Lim MC, Lee B, Jung KW, et al. Changes in ovarian cancer survival during the 20 years before the era of targeted therapy. BMC Cancer. 2018, 18: 601

33. Fuh KC, Shin JY, Kapp DS, Brooks RA, Ueda S, Urban RR, et al. Survival differences of Asian and Caucasian epithelial ovarian cancer patients in the United States. Gynecologic Oncology. 2015, 136(3), 491-497.

34. Liu H, Xu Y, Ji J, Dong R, Qiu H, Dai X. Prognosis of ovarian clear ell cancer compared with other epithelial cancer types: A populationbased analysis. Oncology letters. 2020, 19: 1947-1957.

35. Chang LC, Huang CF, Lai MS, Shen LJ, Wun FLLL, Cheng WF. Prognostic factors in epithelial ovarian cancer: A population-based study. PLoS ONE. 2018,13(3): e0194993

36. Permuth-Wey J and Sellers TA. Epidemiology of ovarian cancer. Methods in Molecular Biology. 2009, 472 (4): $413-437$.

37. Verheijen R and Zweemer R. Screening to improve ovarian cancer prognosis?. The Lancet. 2016, 387: $921-922$.

38. Ishioka S, Sagae S, Ito E, Kudo R. Ultrastructural study of benign, low-malignant potential (LMP), and malignant ovarian tumors. Med Electron Microsc. 2004, 37:37-44.

39. Kurman RJ, Carcangiu ML, Herrington CS, et al. WHO Classification of Tumours of the Female Reproductive Organs. Lyon: WHO Press, 2014.

40. Chiang YC, Chen CA, Chiang CJ, Hsu TH, Lin MC, You SL, et al. Trends in incidence and survival outcome of epithelial ovarian cancer: 30year national population-based registry in Taiwan. J Gynecol Oncol. 2013, 24 (4): 342-351.

41. Madli F, Leong E, Ong SK, Lim E, Tengah KA. Predictive factors associated with survival rate of cervical cancer patients in Brunei Darussalam. Brunei Int Med J. 2019, 15: 125-132.

42. Cortez AJ, Tudrej P, Kujawa KA, Lisowska KM. Advances in ovarian cancer therapy. Cancer chemotherapy and pharmacology. 2018, 81(1): 17-38.

43. Cristea M, Han E, Salmon L, Morgan RJ. Practical considerations in ovarian cancer chemotherapy. Therapeutic advances in medical oncology. 2010, 2(3): 175-187.

44. Raja FA, Chopra N, Ledermann JA. Optimal first-line treatment in ovarian cancer. Annals of Oncology. 2012, 23, $118-127$.

45. Parker D, Bradley C, Bogle SM, Lay J, Masood M, Hancock AK, et al. Serum albumin and CA125 are powerful predictors of survival in epithelial ovarian cancer. Br J Obstet Gynecol. 1994, 101:888-893.

46. Zhang M, Xie Xang, Lee AH, Binns CW, Holman CDJ. Body Mass Index in Relation to Ovarian Cancer Survival. Cancer Epidemiol Biomarkers Prev. 2005, 14(5), 1307-1310.

47. Goode EL, Maurer MJ, Sellers TA, Phelan CM, Kalli KR, Fridley BL, et al. Prognosis of ovarian clear cell cancer compared with other epithelial cancer types: A population-based analysis. Oncology Letters. 2020, 19, 1947-1957.

48. Tan TZ, Ye J, Yee CV, Lim D, Ngoi NYL, Tan DSP, et al. Analysis of gene expression signatures identifies prognostic and functionally distinct ovarian clear cell carcinoma subtypes. EBioMedicine. 2019, 50: 203-210.

\section{Tables}

Table 1: Number, crude, age-standardized incidence rate, and age-standardized mortality rate in 2007-2017, 2007-2011, and $2012-2017$. 


\begin{tabular}{|c|c|c|c|c|c|c|}
\hline \multirow[b]{2}{*}{ Period } & \multicolumn{3}{|c|}{ Incidence } & \multicolumn{3}{|c|}{ Mortality } \\
\hline & $\begin{array}{l}\text { No. of } \\
\text { cases }\end{array}$ & $\begin{array}{l}\text { Crude rate (per } \\
100,000)\end{array}$ & $\begin{array}{l}\text { ASIR }(95 \% \\
\text { CI) }\end{array}$ & $\begin{array}{l}\text { No. of } \\
\text { deaths }\end{array}$ & $\begin{array}{l}\text { Crude rate (per } \\
100,000)\end{array}$ & $\begin{array}{l}\text { ASMR }(95 \% \mathrm{Cl}) \text { per } \\
100,000\end{array}$ \\
\hline & & & per 100,000 & & & \\
\hline $\begin{array}{l}2007- \\
2017\end{array}$ & 207 & 9.7 & $\begin{array}{l}11.3(9.7- \\
12.9)\end{array}$ & 76 & 3.6 & \multirow{4}{*}{$\begin{array}{l}4.5(3.4-5.6) \\
3.0(1.5-4.5) \\
5.6(3.1-8.1)\end{array}$} \\
\hline \multirow{2}{*}{$\begin{array}{l}2007- \\
2011\end{array}$} & \multirow{2}{*}{82} & \multirow{2}{*}{8.7} & \multirow{2}{*}{$\begin{array}{l}11.6(8.9- \\
14.3)\end{array}$} & \multirow{2}{*}{17} & \multirow{2}{*}{1.8} & \\
\hline & & & & & & \\
\hline $\begin{array}{l}2012- \\
2017\end{array}$ & 125 & 10.5 & $\begin{array}{l}11.1(9.1- \\
13.1)\end{array}$ & 59 & 4.9 & \\
\hline
\end{tabular}

ASIR: age-standardized incidence rate, ASMR: age-standardized mortality rate, Cl: Confidence Interval

Table 2: Number of cases, 5-year overall survival rate of epithelial ovarian cancer patients, and $p$-values of log-rank tests

\begin{tabular}{|c|c|c|c|}
\hline Variable & No. of cases, $n(\%)$ & 5-SR $(95 \% \mathrm{Cl})$ & $p$-value ${ }^{a}$ \\
\hline Age at diagnosis (years) & & & $<0.001$ * \\
\hline 40 & $57(27.5)$ & $92.6(81.3-97.2)$ & \\
\hline $40-49$ & $46(22.2)$ & $66.6(49.7-79.0)$ & \\
\hline $50-59$ & $60(29.0)$ & $40.4(26.7-53.6)$ & \\
\hline $60-69$ & $25(12.1)$ & $43.9(19.3-66.2)$ & \\
\hline 70 & $19(9.2)$ & $40.5(18.7-61.5)$ & \\
\hline District & & & 0.229 \\
\hline Brunei Muara & $135(68.2)$ & $57.8(48.4-66.1)$ & \\
\hline Tutong & $32(16.2)$ & $60.6(39.2-76.5)$ & \\
\hline Belait & $27(13.6)$ & $76.2(54.1-88.6)$ & \\
\hline Temburong & $4(2.0)$ & 100.0 & \\
\hline Ethnicity & & & 0.241 \\
\hline Malay & $173(83.6)$ & $58.9(50.7-66.3)$ & \\
\hline Chinese & $22(10.6)$ & $81.8(58.5-92.8)$ & \\
\hline Others & $12(5.8)$ & $64.8(25.3-87.2)$ & \\
\hline Stage & & & $<0.001^{*}$ \\
\hline Localized & $74(38.9)$ & $94.1(85.0-97.8)$ & \\
\hline Regional & $52(27.4)$ & $46.4(31.7-59.8)$ & \\
\hline Distant & $64(33.7)$ & $38.0(25.2-50.7)$ & \\
\hline Histology & & & $<0.001^{*}$ \\
\hline Serous carcinoma & $58(28.0)$ & $62.3(48.1-73.7)$ & \\
\hline Mucinous carcinoma & $64(30.9)$ & $78.5(64.9-87.3)$ & \\
\hline Endometrioid carcinoma & $22(10.6)$ & $55.8(27.4-76.9)$ & \\
\hline Clear cell carcinoma & $11(5.3)$ & $68.2(28.6-88.9)$ & \\
\hline Undifferentiated or other-epithelial & $52(25.1)$ & $39.6(25.7-53.2)$ & \\
\hline
\end{tabular}

Page 10/15 
5-SR: 5-year overall survival rate, Cl: confidence interval, a $p$-value for Log Rank Test, *statistically significant ( $p<0.05)$

Table 3: Number of cases for epithelial ovarian cancer patients according to cancer stage

\begin{tabular}{|c|c|c|c|c|}
\hline \multirow[t]{3}{*}{ Variable } & \multicolumn{3}{|l|}{ Stage } & \multirow[t]{3}{*}{$p$-value ${ }^{\mathrm{a}}$} \\
\hline & Localized & Regional & Distant & \\
\hline & $n(\%)$ & $n(\%)$ & $n(\%)$ & \\
\hline \multicolumn{4}{|l|}{ Age at diagnosis (years) } & \multirow[t]{6}{*}{$<0.001 *$} \\
\hline$<40$ & $37(69.8)$ & $9(17.0)$ & $7(13.2)$ & \\
\hline $40-49$ & $14(32.6)$ & $11(25.6)$ & $18(41.9)$ & \\
\hline $50-59$ & $14(26.4)$ & $24(45.3)$ & $15(28.3)$ & \\
\hline $60-69$ & $7(29.2)$ & $2(8.3)$ & $15(62.5)$ & \\
\hline 70 & $2(11.8)$ & $6(35.3)$ & $9(52.9)$ & \\
\hline \multicolumn{4}{|l|}{ District } & \multirow[t]{5}{*}{0.350} \\
\hline Brunei Muara & $46(37.1)$ & $33(26.6)$ & $45(36.3)$ & \\
\hline Tutong & $12(42.9)$ & $9(32.1)$ & $7(25.0)$ & \\
\hline Belait & $14(53.8)$ & 5 (19.2) & $7(26.9)$ & \\
\hline Temburong & $0(0.0)$ & $2(50.0)$ & $2(50.0)$ & \\
\hline \multicolumn{4}{|l|}{ Ethnicity } & \multirow[t]{4}{*}{0.443} \\
\hline Malay & $60(37.3)$ & $44(27.3)$ & $57(35.4)$ & \\
\hline Chinese & $10(50.0)$ & $4(20.0)$ & $6(30.0)$ & \\
\hline Others & $4(44.4)$ & $4(44.4)$ & $1(11.1)$ & \\
\hline \multicolumn{4}{|l|}{ Histology } & \multirow[t]{6}{*}{$<0.001 *$} \\
\hline Serous carcinoma & $11(21.6)$ & $15(29.4)$ & $25(49.0)$ & \\
\hline Mucinous carcinoma & $42(68.9)$ & $10(16.4)$ & $9(14.8)$ & \\
\hline Endometrioid carcinoma & $8(38.1)$ & $9(42.9)$ & $4(19.0)$ & \\
\hline Clear cell carcinoma & $6(54.5)$ & $3(27.3)$ & $2(18.2)$ & \\
\hline Undifferentiated or other-epithelial & $7(15.2)$ & $15(32.6)$ & $24(52.2)$ & \\
\hline
\end{tabular}

${ }^{\text {a} F i s h e r ' s ~ E x a c t ~ t e s t ~(c o m p a r i n g ~ c a n c e r ~ s t a g e s), ~ * s t a t i s t i c a l l y ~ s i g n i f i c a n t ~}(p<0.05)$

Table 4: Hazard ratio, Adjusted Hazard Ratio, and 95\% confidence intervals of the variables using multivariable Cox PH regression. 


\begin{tabular}{|c|c|c|c|c|}
\hline Variable & $\mathrm{HR}(95 \% \mathrm{Cl})$ & $p$-value ${ }^{a}$ & Adj. HR $(95 \% \mathrm{Cl})$ & $p$-value ${ }^{\mathrm{b}}$ \\
\hline \multicolumn{5}{|l|}{ Age at diagnosis } \\
\hline $40^{r}$ & 1.00 & - & 1.00 & - \\
\hline $40-49$ & $2.18(0.74-6.41)$ & 0.157 & $2.02(0.69-5.90)$ & 0.198 \\
\hline $50-59$ & $5.36(2.02-14.23)$ & $0.001 *$ & $5.29(1.99-14.05)$ & $0.001 *$ \\
\hline $60-69$ & $2.82(0.89-8.93)$ & 0.077 & $2.45(0.79-7.60)$ & 0.122 \\
\hline 70 & $7.86(2.42-25.53)$ & $0.001 *$ & $7.21(2.24-23.23)$ & $0.001^{*}$ \\
\hline \multicolumn{5}{|l|}{ District } \\
\hline Brunei Muara $^{r}$ & 1.00 & - & 1.00 & - \\
\hline Tutong & $0.72(0.36-1.44)$ & 0.349 & $0.75(0.37-1.51)$ & 0.413 \\
\hline Belait & $0.36(0.13-0.98)$ & $0.046^{*}$ & $0.31(0.12-0.80)$ & $0.015^{\star}$ \\
\hline Temburong & $0.00(0.00-)$ & 0.996 & $0.00(0.00-)$ & 0.996 \\
\hline \multicolumn{5}{|l|}{ Ethnicity } \\
\hline Malay $^{r}$ & 1.00 & - & & \\
\hline Chinese & $0.49(0.16-1.48)$ & 0.206 & & \\
\hline Others & $1.06(0.30-3.74)$ & 0.925 & & \\
\hline \multicolumn{5}{|l|}{ Stage } \\
\hline Localized $^{r}$ & 1.00 & - & 1.00 & - \\
\hline Regional & $6.02(2.22-16.29)$ & $<0.001^{*}$ & $6.12(2.26-16.56)$ & $<0.001 *$ \\
\hline Distant & $11.91(4.42-32.09)$ & $<0.001^{\star}$ & $11.99(4.46-32.23)$ & $<0.001^{*}$ \\
\hline \multicolumn{5}{|l|}{ Histology } \\
\hline Serous carcinomar ${ }^{r}$ & 1.00 & - & 1.00 & - \\
\hline Mucinous carcinoma & $1.77(0.82-3.86)$ & 0.146 & $1.75(0.81-3.79)$ & 0.153 \\
\hline Endometrioid carcinoma & $2.24(0.91-5.53)$ & 0.080 & $1.97(0.81-4.78)$ & 0.132 \\
\hline Clear cell carcinoma & $1.27(0.35-4.59)$ & 0.717 & $1.33(0.37-4.74)$ & 0.664 \\
\hline Undifferentiated or other-epithelial & $3.13(1.63-6.01)$ & $0.001 *$ & $3.12(1.63-5.95)$ & $0.001^{*}$ \\
\hline
\end{tabular}

HR: Hazard Ratios, Cl: confidence interval, Adj: Adjusted, a $p$-value for Wald statistics, badjusted for Age at diagnosis, Ethnicity, Stage and Histology, ${ }^{r}$ reference level, * ${ }^{*}$ tatistically significant $(p<0.05)$

\section{Figures}




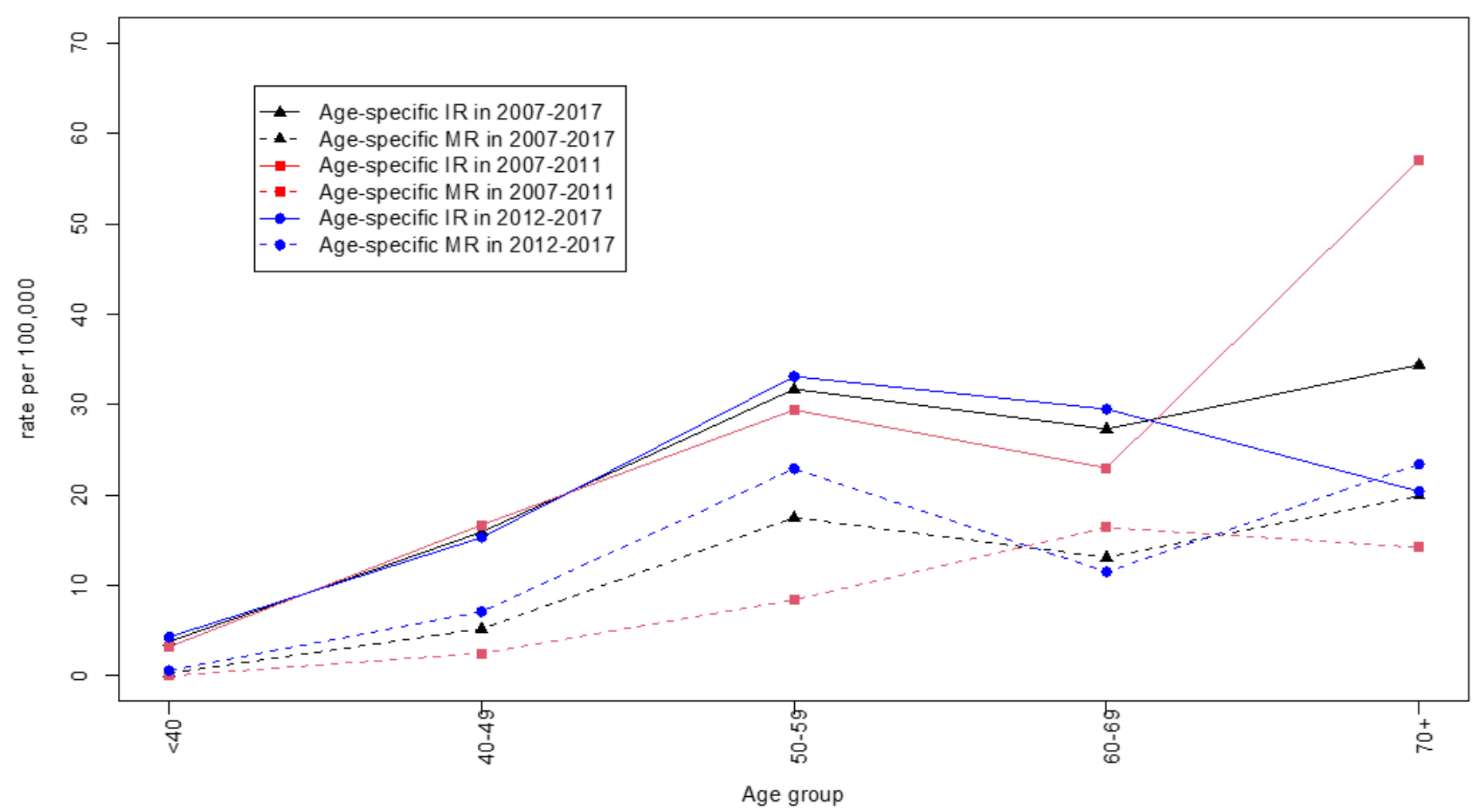

Figure 1

Age-specific incidence rate and mortality rates (per 100,000) by age group in 2007-2017, 2007-2011 and 2012-2017

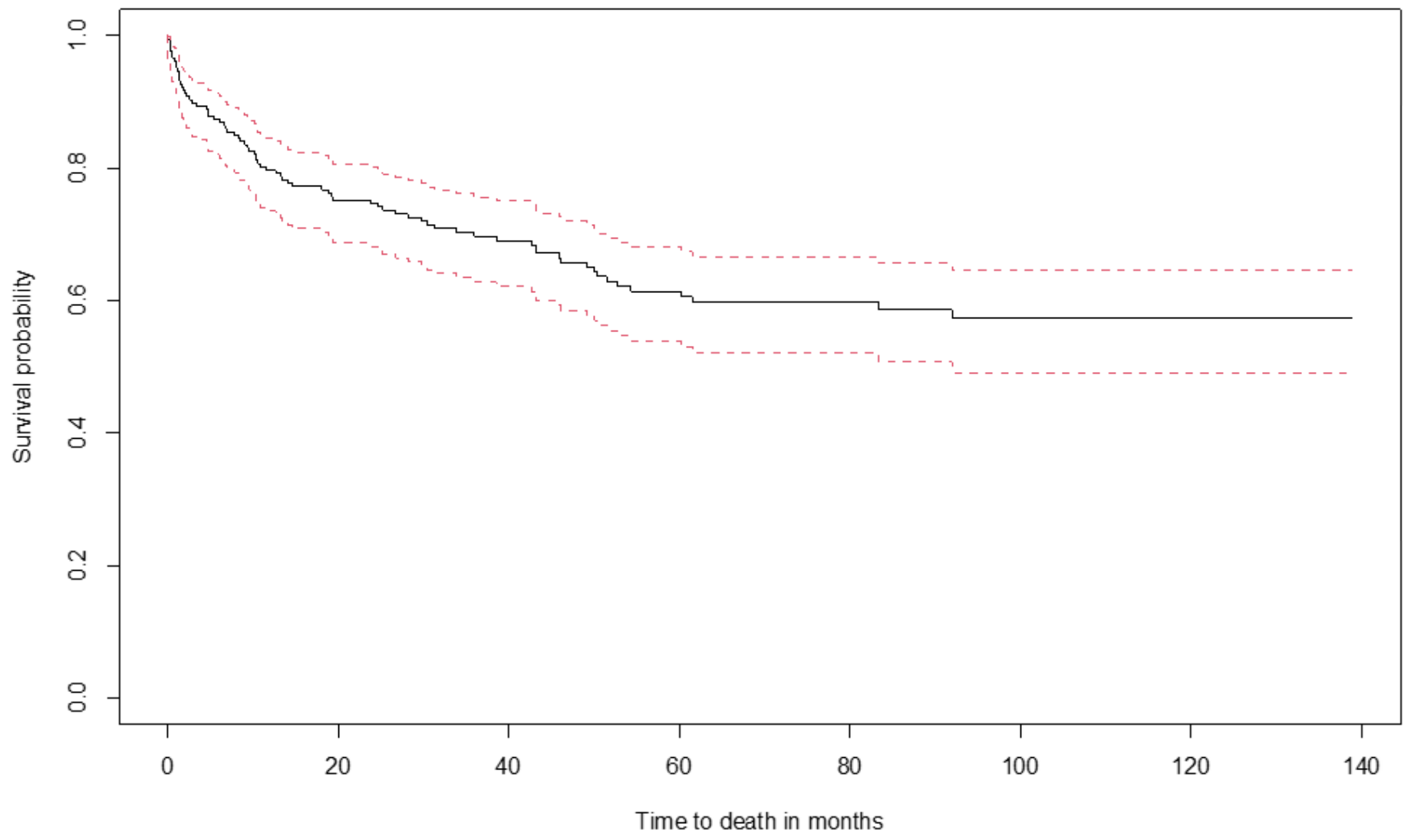

Figure 2

Page $13 / 15$ 
Kaplan-Meier overall survival curve of epithelial ovarian cancer patients

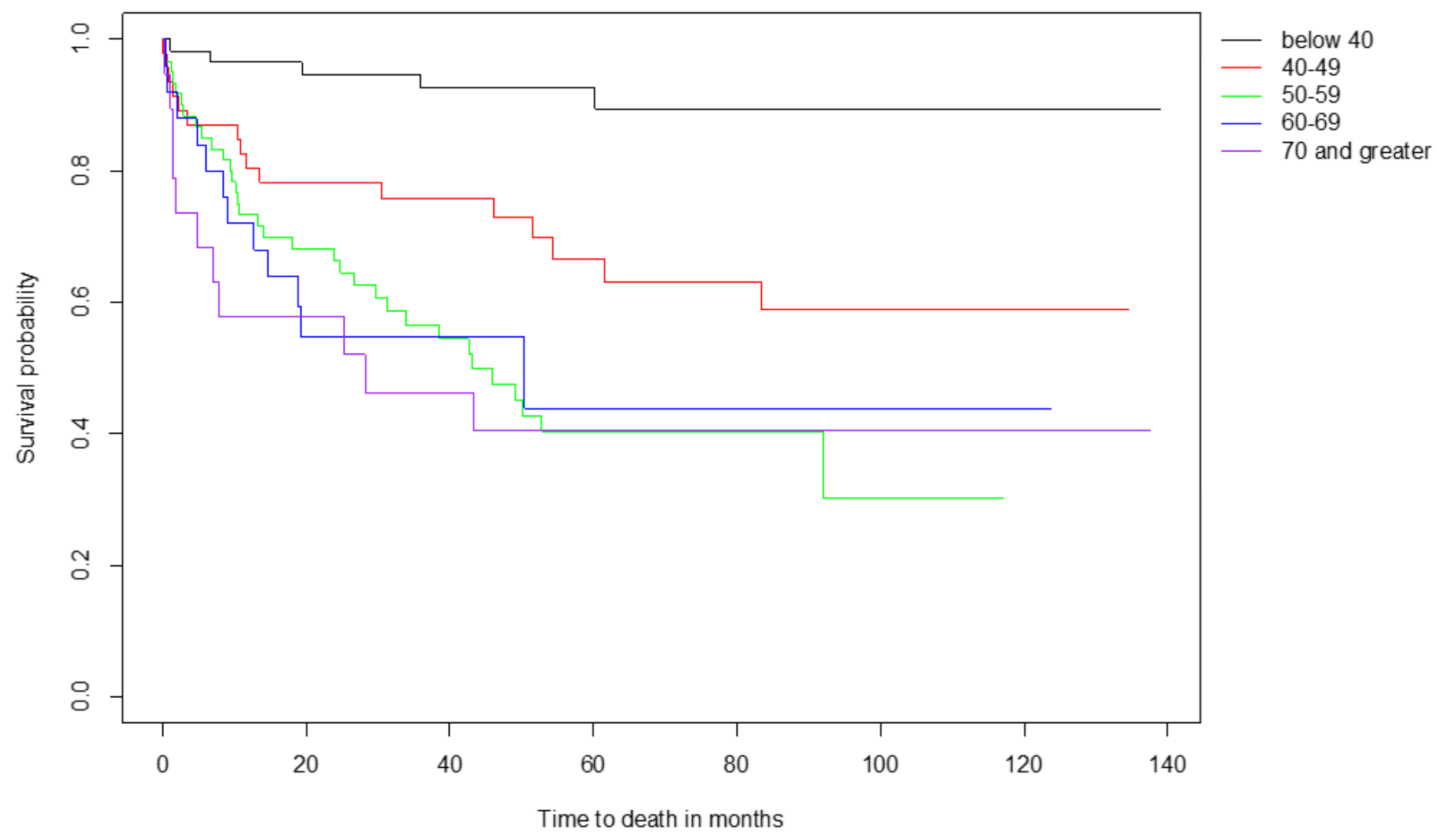

Figure 3

Kaplan-Meier overall survival curves for epithelial ovarian cancer patients by age group

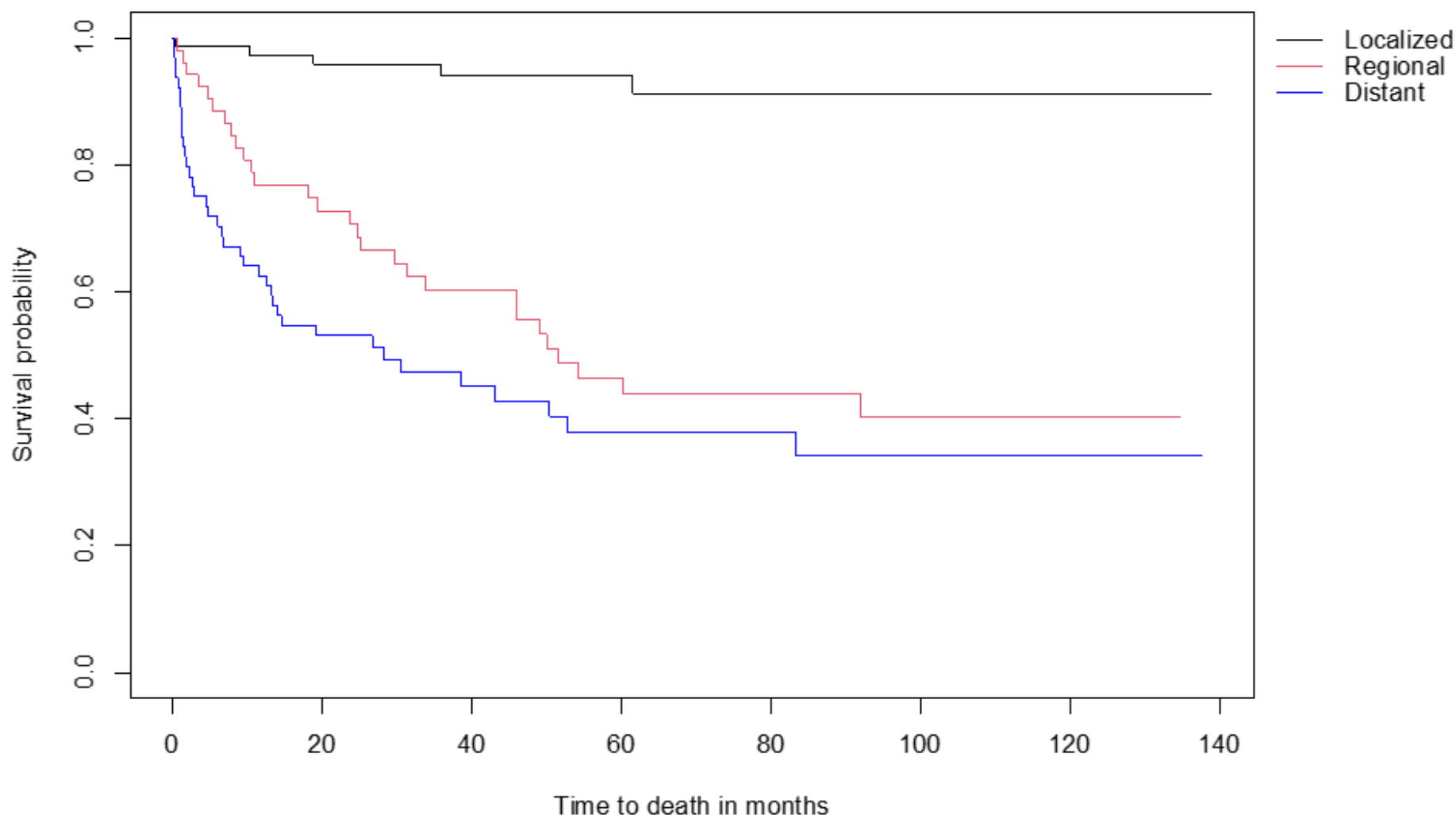


Figure 4

Kaplan-Meier overall survival curves for epithelial ovarian cancer patients by cancer stage

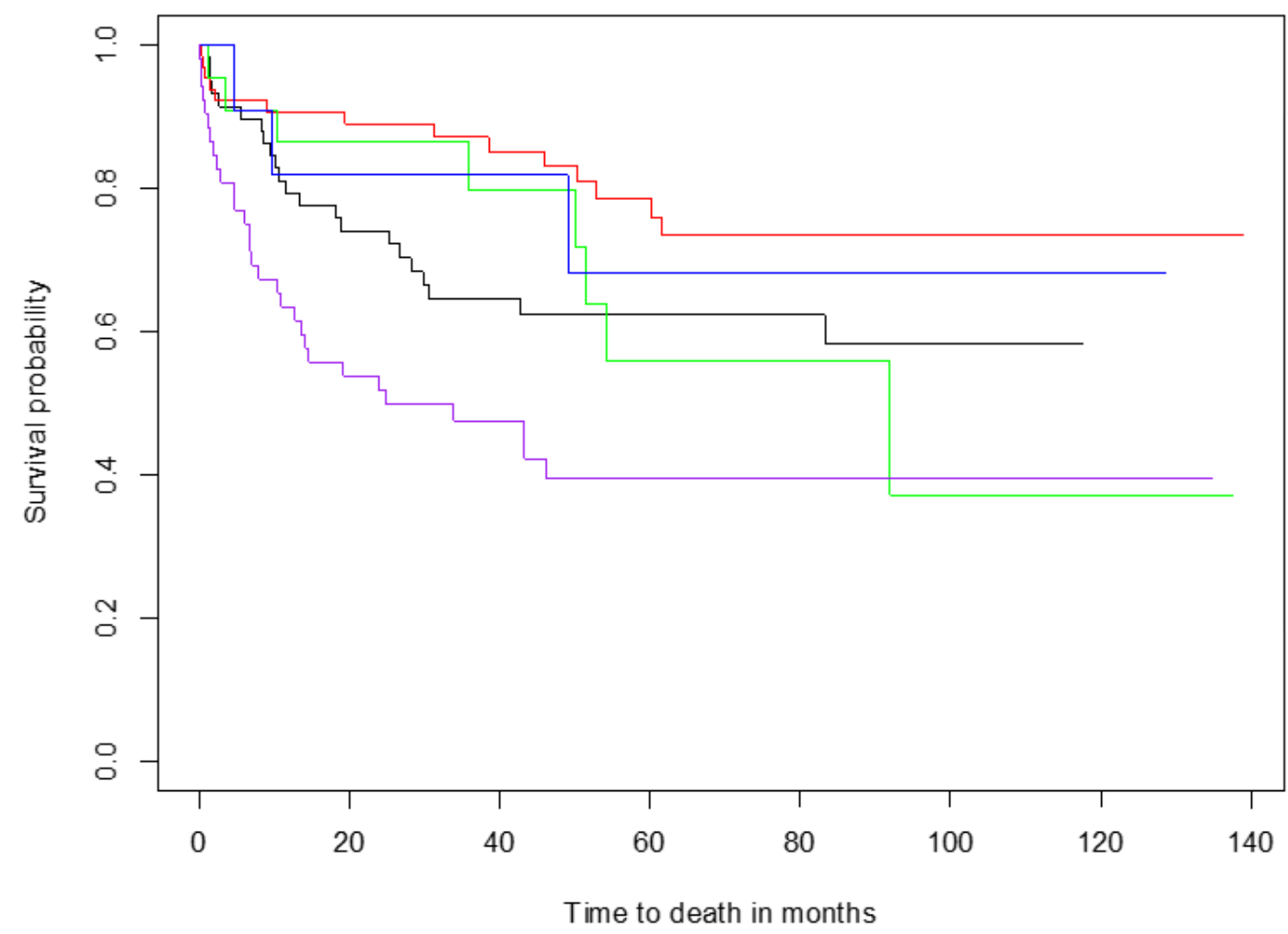

Serous carcinoma Mucinous carcinoma Endometrioid carcinoma Clear cell carcinoma Undifferentiated or other epithelial

Figure 5

Kaplan-Meier overall survival curves for epithelial ovarian cancer patients by histology types 